\title{
A Retrospective Study of Patients with GABA $B$ $R$ Encephalitis: Therapy, Disease Activity and Prognostic Factors
}

This article was published in the following Dove Press journal: Neuropsychiatric Disease and Treatment

\author{
Xiangchuan Wen' \\ Baojie Wang' \\ Chunjuan Wang ${ }^{1,2}$ \\ Chenglin $\mathrm{Han}^{3}$ \\ Shougang Guo $\mathbb{D}^{1,2}$ \\ 'Department of Neurology, Shandong \\ Provincial Hospital, Cheeloo College of \\ Medicine, Shandong University, Jinan, \\ Shandong 25002I, People's Republic of \\ China; ${ }^{2}$ Department of Neurology, \\ Shandong Provincial Hospital Affiliated to \\ Shandong First Medical University, Jinan, \\ Shandong 25002I, People's Republic of \\ China; ${ }^{3}$ Department of Urology, \\ Shandong Provincial Hospital, Cheeloo \\ College of Medicine, Shandong \\ University, Jinan, Shandong 25002I, \\ People's Republic of China
}

Correspondence: Shougang Guo Department of Neurology, Shandong Provincial Hospital, Cheeloo College of Medicine, Shandong University, Jing Wu Road, Huaiyin District, Jinan, 25002I

Shandong, People's Republic of China Tel +86-।322058508।

Email guoshougangII24@I63.com
Purpose: To explore the effects of immunotherapy and tumour treatment on patients with $\mathrm{GABA}_{\mathrm{B}} \mathrm{R}$ encephalitis, evaluate the correlation between immune cell subsets and disease activity, and investigate effective prognostic factors.

Patients and Methods: Twenty patients with $\gamma$-aminobutyric acid $B$ receptor $\left(\mathrm{GABA}_{\mathrm{B}} \mathrm{R}\right)$ encephalitis were enrolled from December 2015 to April 2020. The clinical data, modified Rankin Scale (mRS) score, prognosis and percentage of serum lymphocytes were recorded. Results: All patients received first-line immunotherapy. The median mRS scores were 4 and 3 before and after first-line immunotherapy $(\mathrm{P}<0.01)$. Seven patients received second-line immunotherapy and had median mRS scores of 3 and 2 before and after second-line immunotherapy ( $\mathrm{P}=0.015)$. Small-cell lung cancer was detected in twelve patients. Among the patients who died because of tumours, patients who received tumour treatment lived longer than patients who did not receive tumour treatment $(\mathrm{P}=0.025)$. All four surviving patients who received tumour treatment had good outcomes $(\mathrm{mRS} \leq 2)$. The median serum $\mathrm{CD} 19^{+} \mathrm{B}$ cell percentage in sixteen patients were $20.00 \%$ and $13.42 \%$ prior first-line immunotherapy and at the last follow-up $(\mathrm{P}<0.01)$. After a maximum follow-up of 54 months (median: 12; range: $3-54)$, eleven patients $(55 \%)$ had a poor prognosis $(\mathrm{mRS}>2)$. Predictors of a poor prognosis were older age $(\mathrm{P}=0.031)$, delayed initial improvement after immunotherapy ( $>4$ weeks $)(\mathrm{P}=0.038)$ and respiratory failure $(\mathrm{P}=0.038)$.

Conclusion: Aggressive immunotherapy and tumour treatment contribute to improvements in neurological function and a better prognosis of patients with $\mathrm{GABA}_{\mathrm{B}} \mathrm{R}$ encephalitis. The serum $\mathrm{CD} 19^{+} \mathrm{B}$ cell percentage may be an indicator of disease activity. Older age, delayed initial improvement after immunotherapy, and respiratory failure may be associated with poor outcomes.

Keywords: $\mathrm{GABA}_{\mathrm{B}} \mathrm{R}$ encephalitis, immunotherapy, tumour treatment, $\mathrm{CD} 19^{+} \mathrm{B}$ cell percentage, prognosis

\section{Introduction}

Since the discovery of anti-N-methyl-D-aspartate receptor (NMDAR) encephalitis in $2007,{ }^{1}$ a series of autoantibodies against neuronal cell surface or synaptic proteins, such as anti-leucine-rich glial inactivating protein 1 (LGI-1) antibodies and anti- $\gamma$-aminobutyric acid $\mathrm{B}\left(\mathrm{GABA}_{\mathrm{B}}\right)$ receptor antibodies, have been discovered in succession. ${ }^{2}$ In contrast to the classic paraneoplastic neurological syndrome, B cell-based humoral immunity plays an important role in the pathogenesis. Due to the pathogenic effects of specific antibodies, patients respond well to immunotherapy. ${ }^{3}$ GABA $_{B}$ receptors $\left(\mathrm{GABA}_{\mathrm{B}} \mathrm{Rs}\right)$ are $\mathrm{G}$ protein-coupled receptors 
involved in the regulation of glutamate signalling and play an important role in neurotransmitter transmission and synaptic stability. ${ }^{4} \mathrm{GABA}_{\mathrm{B}} \mathrm{R}$ encephalitis was first reported in $2010 .^{5}$ These antibodies have a mode of action similar to the NMDAR antibodies by altering the receptor density, and clinical manifestations are similar to NMDAR encephalitis, with prominent cognitive decline, memory problems, psychotic episodes and seizures. Patients with $\mathrm{GABA}_{\mathrm{B}} \mathrm{R}$ encephalitis have also been reported to develop coexisting (or overlapping) autoantibodies, such as antibodies targeting voltage-gated calcium channels (VGCCs), glutamic acid decarboxylase 65 (GAD65), and sex determining region Y-box 1 (SOX1). ${ }^{6,7}$ Approximately 50\% of patients have tumours, $92 \%$ of which are small-cell lung cancer (SCLC). ${ }^{8}$ The five-year survival rate of patients with SCLC is less than $10 \%,{ }^{9}$ which affects the prognosis of patients. Due to the rarity of this disease, few studies have focused on it, and the understanding of this disease is limited. This retrospective study aimed to examine the effects of immunotherapy and tumour treatment on patients with $\mathrm{GABA}_{\mathrm{B}} \mathrm{R}$ encephalitis, to determine the percentage of serum lymphocytes at different stages of the disease, and to identify factors related to disease prognosis.

\section{Methods}

\section{Patients}

Study cases came from a series of 624 patients who presented to the Provincial Hospital Affiliated to Shandong University from December 2015 to April 2020. The patients included fulfilled the following criteria in the study: $^{10}$ (1) acute or subacute onset (<3 months); (2) symptomatic manifestations of encephalitis; (3) $\mathrm{GABA}_{\mathrm{B}}$ $\mathrm{R}$ antibody positivity in serum and/or cerebrospinal fluid (CSF); and (4) no intracranial infectious, traumatic, toxic, metabolic, intracranial neoplastic or demyelinating diseases. All patients were tested for cell surface antigen antibodies against the GABAB receptor, NMDA receptor, AMPA receptor, LGI1 and CASPR2 receptor by cell-based assay (CBA) on human embryonic kidney (HEK 293) cells transfected with plasmids in serum and CSF. Classic paraneoplastic autoantibodies (anti-Hu, -Yo, -Ri, -CV2 /CRMP5, -amphiphysin and -Ma2/Ta) were also detected by immunoblot assay in serum. All samples were sent to EUROIMMUN Medical Diagnostics in Hangzhou, China for testing. The study was approved by the Research
Ethics Committee of Shandong Provincial Hospital Affiliated to Shandong University.

\section{Assessment of Clinical Information}

The demographic characteristics, clinical manifestations, results of auxiliary examinations, treatment strategies and prognosis were collected by professional neurologists through a review of data collected during hospitalization and telephone and outpatient follow-up. All patients were analysed using continuous electroencephalography (EEG) monitoring $(24 \mathrm{~h})$, brain magnetic resonance imaging (MRI) and CSF assays. Contrast-enhanced computed tomography (CT) was performed to assess the presence of tumours. $\mathrm{GABA}_{\mathrm{B}} \mathrm{R}$ antibody titres were categorized as weakly positive $(<1: 10)$, positive $(<1: 100)$ and strongly positive $(\geq 1: 100)$.

\section{Treatment and Follow-Up}

Patients received first-line immunotherapy, second-line immunotherapy and tumour treatment when needed. ${ }^{11,12}$ Relapse was defined as symptoms that reappeared or were aggravated when neurological function had improved or stabilized for more than 2 months. ${ }^{13}$ Neurological deficits before and after treatment and during follow-up were evaluated with the modified Rankin Scale (mRS). According to the mRS score at the last follow-up, patients were divided into groups with a good prognosis $(\mathrm{mRS} \leq 2)$ and poor prognosis $(\mathrm{mRS}>2) .{ }^{14}$

\section{Statistical Analysis}

SPSS version 21.0 (IBM Corporation, Armonk, NY, USA) software was used for the statistical analysis, and GraphPad Prism7 (GraphPad Software Inc., La Jolla, CA, USA) software was used to generate graphs. Continuous variables with normal distribution are presented as means \pm standard deviations (SD), while the other continuous variables are presented as medians and range values. Continuous variables with normal distribution were compared using t-tests, and continuous variables with non-normal distributions were compared using the Mann-Whitney U-test. Categorical values are reported as frequencies (percentage, \%) and were compared using Fisher's exact test. The survival analysis was performed using the Kaplan-Meier method, and differences were compared using the Log rank test. Probability values of $\mathrm{P}<0.05$ were considered statistically significant. 


\section{Results}

\section{Clinical Characteristics}

Of 624 patients with encephalitis of unknown etiology, 20 patients $(3.21 \%)$ with $\mathrm{GABA}_{\mathrm{B}} \mathrm{R}$ encephalitis who met the diagnostic criteria were included, of whom twelve $(60 \%)$ were male. The average age at disease onset was 59.35 \pm 9.20 years (range: $35-72$ years). Ten patients $(50 \%)$ had a long-term smoking history, and three patients $(15 \%)$ presented with prodromal symptoms of fever or diarrhoea in the week prior to the onset. None of the patients had a history of autoimmune diseases. The median time from onset to diagnosis was 16 days (range: $7-130$ days). The demographic and clinical characteristics are summarized in Table 1. Seizures occurred in eighteen patients (90\%), all of which were generalized tonic-clonic seizures (GTCS). Sixteen $(80 \%)$ patients had seizures as the initial symptom, and ten $(50 \%)$ developed status epilepticus (SE). Seventeen patients (85\%) had cognitive impairment, as manifested by decreased memory, orientation, and calculation skills. Disturbance of consciousness was observed in fourteen patients (70\%). Furthermore, psychiatric symptoms, including changes in behaviour, mood, and personality were documented in fourteen patients $(70 \%)$. In addition to limbic symptoms, two patients $(10 \%)$ presented with extralimbic symptoms: one showed symptoms of gait ataxia, and brainstem encephalitis was observed in another. Ten patients $(50 \%)$ had lung infections, and five patients $(25 \%)$ who developed respiratory failure were subjected to tracheal intubation and mechanical ventilation. Four (20\%) patients were admitted to the intensive care unit (ICU): three who required mechanical ventilation and one who had SE.

\section{Auxiliary Examinations}

Eighteen patients $(90 \%)$ were positive for $\mathrm{GABA}_{\mathrm{B}}$ $\mathrm{R}$ antibodies in both serum and CSF. One patient was positive only in CSF, and another was positive only in serum. The median antibody titre was 1:32 (1:10-1:100) in serum and 1:10 in CSF (1:1-1:100). All patients tested negative for autoantibodies against NMDAR, AMPAR1, AMPAR2, LGI1, and Caspr2. Anti-Hu antibodies were detected in serum of one patient.

In the CSF assay, the opening pressure was high $(>180$ $\left.\mathrm{mmH}_{2} \mathrm{O}\right)$ in two patients $(10 \%)$. White blood cell counts were elevated $\left(>8\right.$ cells $/ \mathrm{mm}^{3}$ ) in fifteen patients (range: $0-118$ cells $/ \mathrm{mm}^{3}$; median: 16 cells $/ \mathrm{mm}^{3}$ ). Protein levels in CSF were elevated $(>0.45 \mathrm{~g} / \mathrm{L})$ in five patients $(20 \%)$ (range: $0.19-0.66 \mathrm{~g} / \mathrm{L}$; median: $0.36 \mathrm{~g} / \mathrm{L}$ ). Both white blood cell counts and protein levels were elevated in four patients $(20 \%)$ and within the normal range in four patients (20\%). All patients had negative results from a polymerase chain reaction-based assay for viral infection in CSF.

The percentage of serum lymphocytes was measured before immunotherapy in 16 patients. The median percentage of $\mathrm{CD}^{+} \mathrm{T}$ cells was 38.01 (20.15-51.06\%), $\mathrm{CD} 8^{+}$ $\mathrm{T}$ cells was $27.6 \%(10.16-33.59 \%)$, and $\mathrm{CD} 19^{+} \mathrm{B}$ cells was $20.00 \%$ (11.99-33.93\%).

The brain MRI lesions of 11 patients (55\%) were considered related to $\mathrm{GABA}_{\mathrm{B}} \mathrm{R}$ encephalitis, with ten $(50 \%)$ ( 4 cases were bilateral and 6 cases were unilateral) showing an involvement of the limbic system, including the temporal lobe and hippocampus, which manifested as an increasing T2/fluid-attenuated inversion recovery (FLAIR) signal. In addition, one patient had a lesion on the dorsal medulla oblongata (Figure 1).

Five patients $(25 \%)$ showed normal results on continuous EEG monitoring ( $24 \mathrm{~h}$ ), while the remaining fifteen (75\%) had EEG abnormalities. Eight patients (40\%) showed generalized or predominantly temporal slow activity. Furthermore, epileptiform activity was confirmed by continuous EEG monitoring in eight patients (Figure 2).

Three patients underwent whole-body FDG-positron emission tomography (PET) scanning: one patient presented with lung cancer, one showed bilateral hippocampal hypermetabolism, and another had normal results. Contrast-enhanced CT scans were performed to detect tumours in all patients. Twelve patients $(60 \%)$ were diagnosed with SCLC through a fiberscope biopsy, and no other tumours were detected. Notably, in two patients, tumours were not detected at the initial screen at the onset of disease but were found 6 months after discharge.

\section{Immunotherapy}

The median time from onset to the start of immunotherapy was 16 days (range: 6-130 days). All patients received first-line immunotherapy: twenty patients received methylprednisolone (MTP) $(500 \mathrm{mg} / \mathrm{d}$ for 3-5 days), and fifteen patients $(75 \%)$ were also treated with intravenous immunoglobulin (IVIG; $0.4 \mathrm{~g} / \mathrm{kg}$ /day for 5 days). The median neurological function scores evaluated using $\mathrm{mRS}$ of all patients were 4 (range: 3-5) prior to first-line immunotherapy and 3 (range: 2-5) after first-line immunotherapy $(\mathrm{P}<0.01)$. Neurological improvements were observed within 10 days after the initiation of first-line 


\begin{tabular}{|c|c|c|c|c|c|c|c|}
\hline 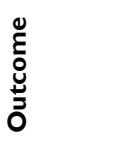 & 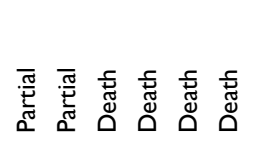 & 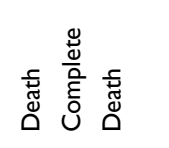 & 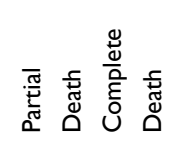 & $\begin{array}{l}\stackrel{5}{\mathbb{E}} \\
\text { Q }\end{array}$ & 易 & 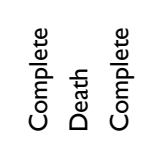 & 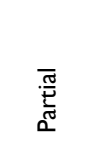 \\
\hline 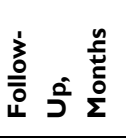 & $=\dot{t} \pm m \underline{n}$ n & 으 요 $\simeq$ & $\tilde{m} \subseteq \neq \simeq$ & $=$ & $\stackrel{m}{2} \simeq$ & in $n$ & in \\
\hline 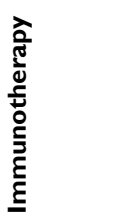 & 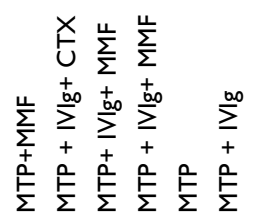 & 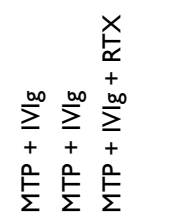 & 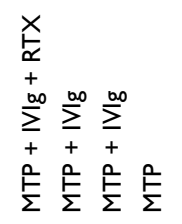 & $\begin{array}{l}\sum_{2}^{\infty} \\
+ \\
+ \\
\sum\end{array}$ & 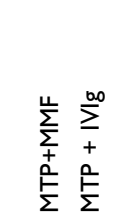 & $\begin{array}{lll}\sum^{\infty} & & \sum^{n 0} \\
+ & + \\
0 & 0 & 0 \\
\Sigma & \Sigma & \Sigma\end{array}$ & $\begin{array}{l}\sum_{20}^{\infty} \\
+ \\
0 \\
\Sigma\end{array}$ \\
\hline 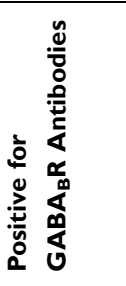 & 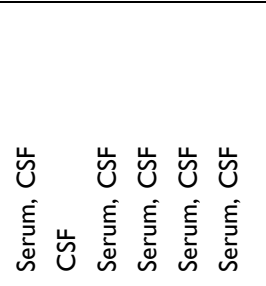 & 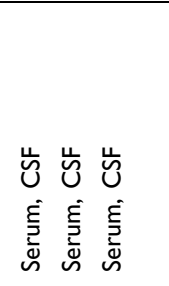 & 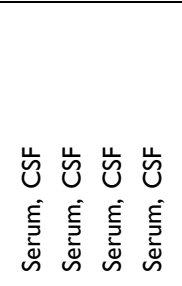 & 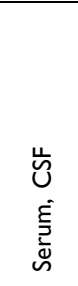 & 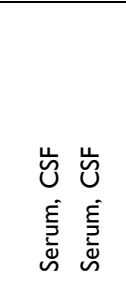 & 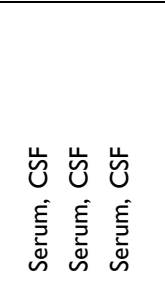 & छ్ \\
\hline שֶ & 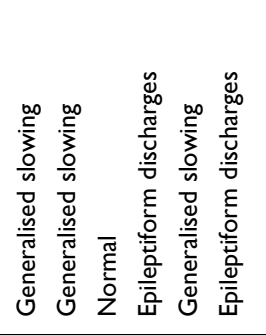 & 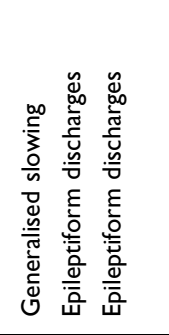 & 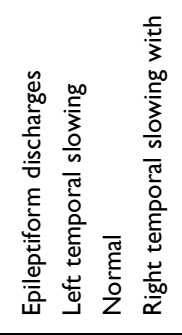 & 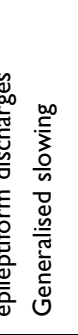 & 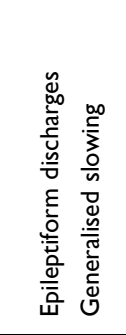 & 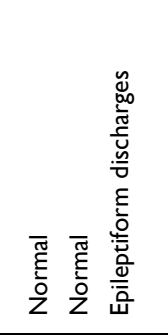 & 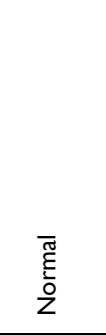 \\
\hline 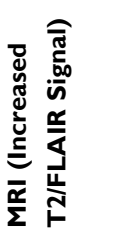 & 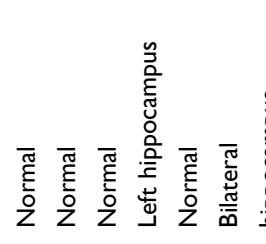 & 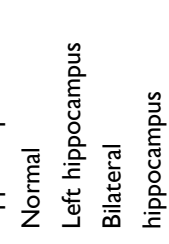 & 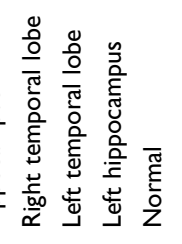 & $\begin{array}{l}\overline{\bar{v}} \\
\frac{\bar{\xi}}{2} \\
z\end{array}$ & 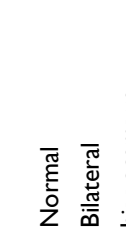 & 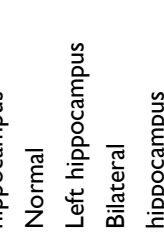 & 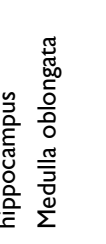 \\
\hline 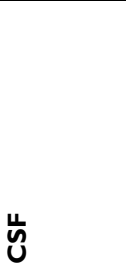 & 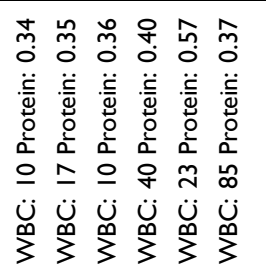 & 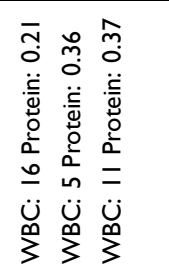 & 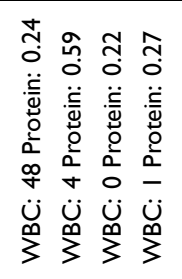 & 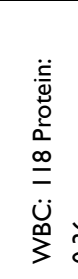 & 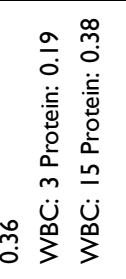 & 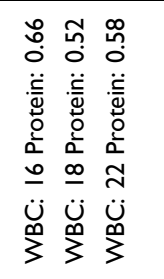 & 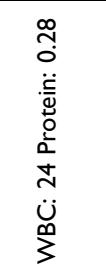 \\
\hline 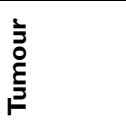 & 岂 号 岂 & 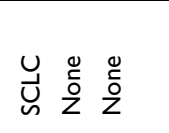 & 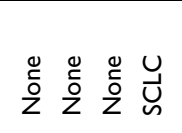 & $\underset{u}{u}$ & 巳ั U⿱艹 & 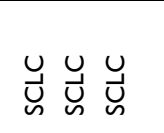 & $\stackrel{0}{\check{0}}$ \\
\hline 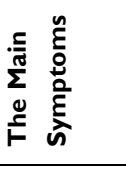 & 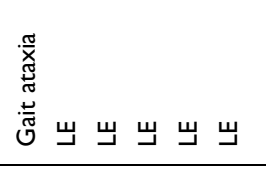 & щ щ & щ щ щ щ & щ & щ & щ щ щ & 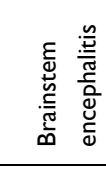 \\
\hline 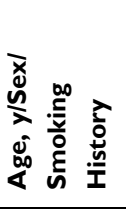 & 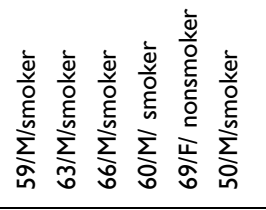 & 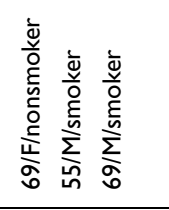 & 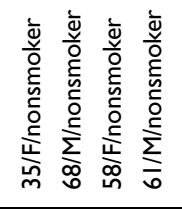 & 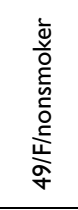 & 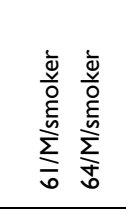 & 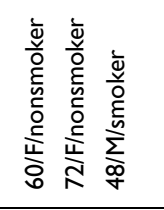 & 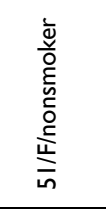 \\
\hline 므 & $-N m+n o$ & $\wedge \infty a$ & $\underline{0}=\simeq \underline{m}$ & \pm & $\underline{ㅇ ㅡ ㄴ ㅡ ㄴ ~}$ & $\simeq \underline{\infty} \underline{a}$ & 요 \\
\hline
\end{tabular}



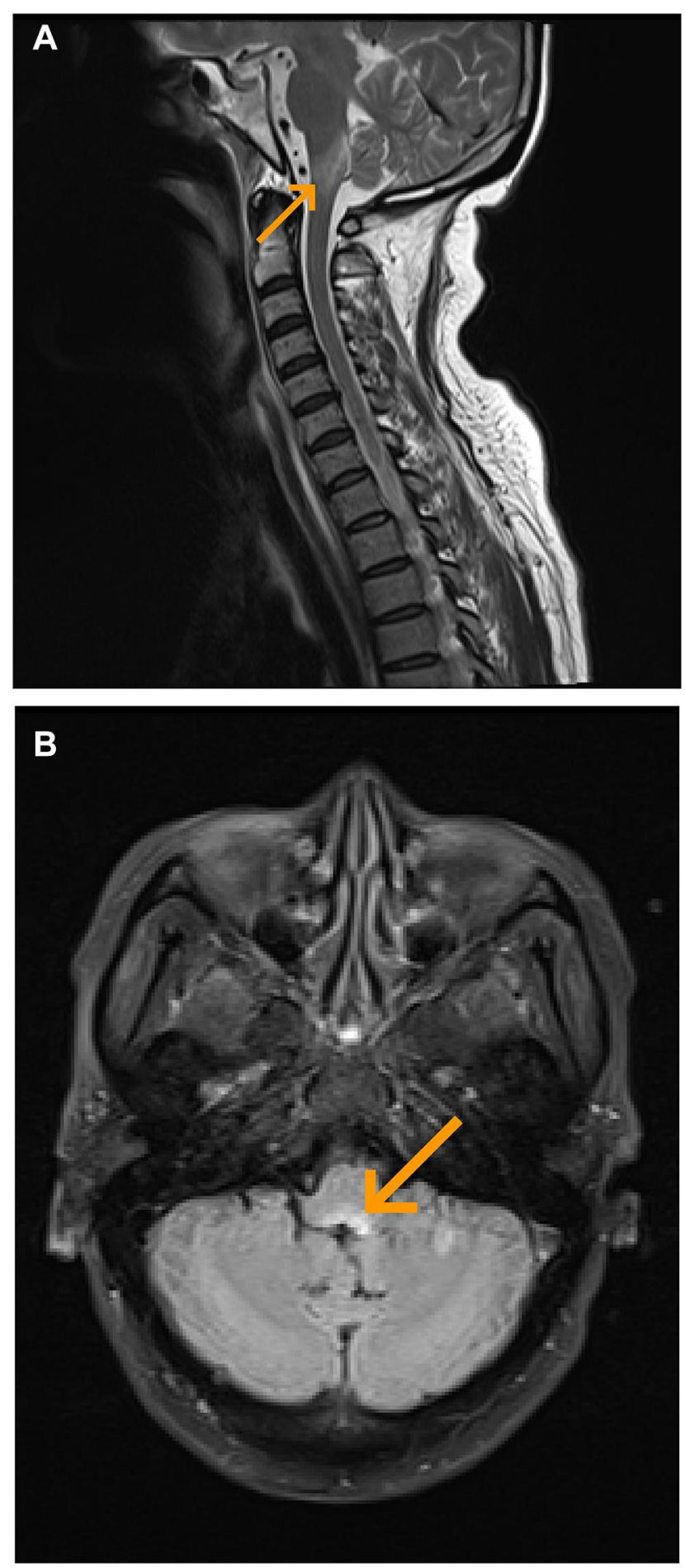

Figure I MRI of patient 20 showing abnormal signals in the medulla oblongata as indicated by arrows. (A) T2-weighted cerebral MRI. (B) FLAIR sequences.

immunotherapy in fourteen patients $(70 \%)$. Seven patients (35\%) received second-line immunotherapy, including two patients treated with rituximab, one patient treated with cyclophosphamide, and four patients treated with mycophenolate mofetil. The median mRS scores of the seven patients were 3 (range: 2-5) and 2 (range: $1-3$ ) before and after second-line therapy $(\mathrm{P}=0.015)$, respectively.

\section{Tumour Treatment}

Twelve patients $(60 \%)$ had a history of tumours, all of whom were diagnosed with SCLC. The median time from the onset of neurological symptoms to the detection of tumour was 26 days (range: 17-260 days). The treatment and survival of patients with SCLC are summarized in Figure 3. Nine patients $(9 / 12 ; 75 \%)$ received tumour treatment, which included chemotherapy and radiotherapy in eight patients and only chemotherapy in one patient. Five patients $(5 / 9 ; 55.6 \%)$ who received tumour treatment died, and the median time from the diagnosis of encephalitis to death was 15 (10-36) months. All three patients (3/3; $100 \%$ ) who did not receive tumour treatment died, and the median time from the diagnosis of encephalitis to death was 5 (3-7) months. Among the patients who died because of tumours, patients who received tumour treatment lived longer than patients who did not receive tumour treatment $(\mathrm{P}=0.025)$. After a median follow-up period of 11.5 (range: 3-20) months, the neurological function of all four surviving patients who received tumour treatment showed good outcomes $(\mathrm{mRS} \leq 2)$, and three of them achieved complete recovery ( $\mathrm{mRS}=0$ ).

Overall survival was defined as the period between the date of disease diagnosis until the last follow-up or death. According to Kaplan-Meier survival estimates, a statistically significant association was observed between the survival rate and the presence of a tumour ( $\log$ rank test, $\mathrm{P}=0.036$ ) (Figure 4).

\section{Follow-Up}

After a median follow-up period of 12 months (range: 3-54 months), nine patients (45\%) showed complete or partial neurological remission $(\mathrm{mRS} \leq 2)$. Ten patients died $(50 \%)$ due to tumour progression $(8 / 10)$, severe lung infection $(1 / 10)$, and SE $(1 / 10)$. One patient $(5 \%)$ experienced a severe cognitive impairment $(\mathrm{mRS}=3)$. The serum antibody titre in the remission phase of disease was measured in three patients, and the patients became negative for antibodies. The percentage of serum lymphocytes was measured in fourteen patients at the last follow-up. The median percentage of $\mathrm{CD}^{+} \mathrm{T}$ cells was $32.04 \%$ (31.29-$39.61 \%), \mathrm{CD}^{+} \mathrm{T}$ cells was $36.0 \%(22.03-39.18 \%)$, and $\mathrm{CD} 19^{+} \mathrm{B}$ cells was $13.42 \%$ (range: $8.71-18.23 \%$ ). The serum $\mathrm{CD} 19^{+} \mathrm{B}$ cell percentage in the remission phase was significantly lower than in the acute phase $(\mathrm{P}<0.01)$ 


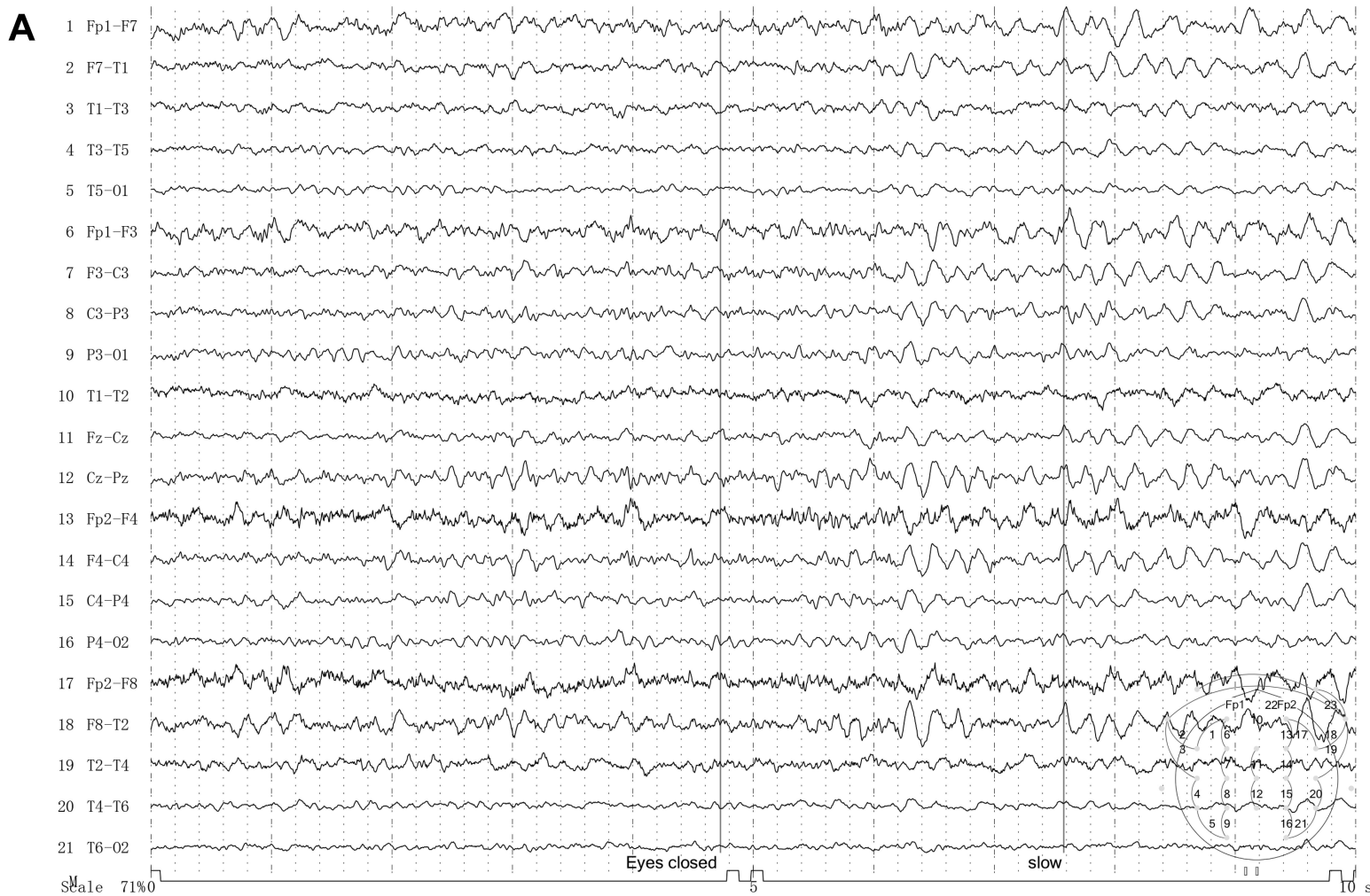

B

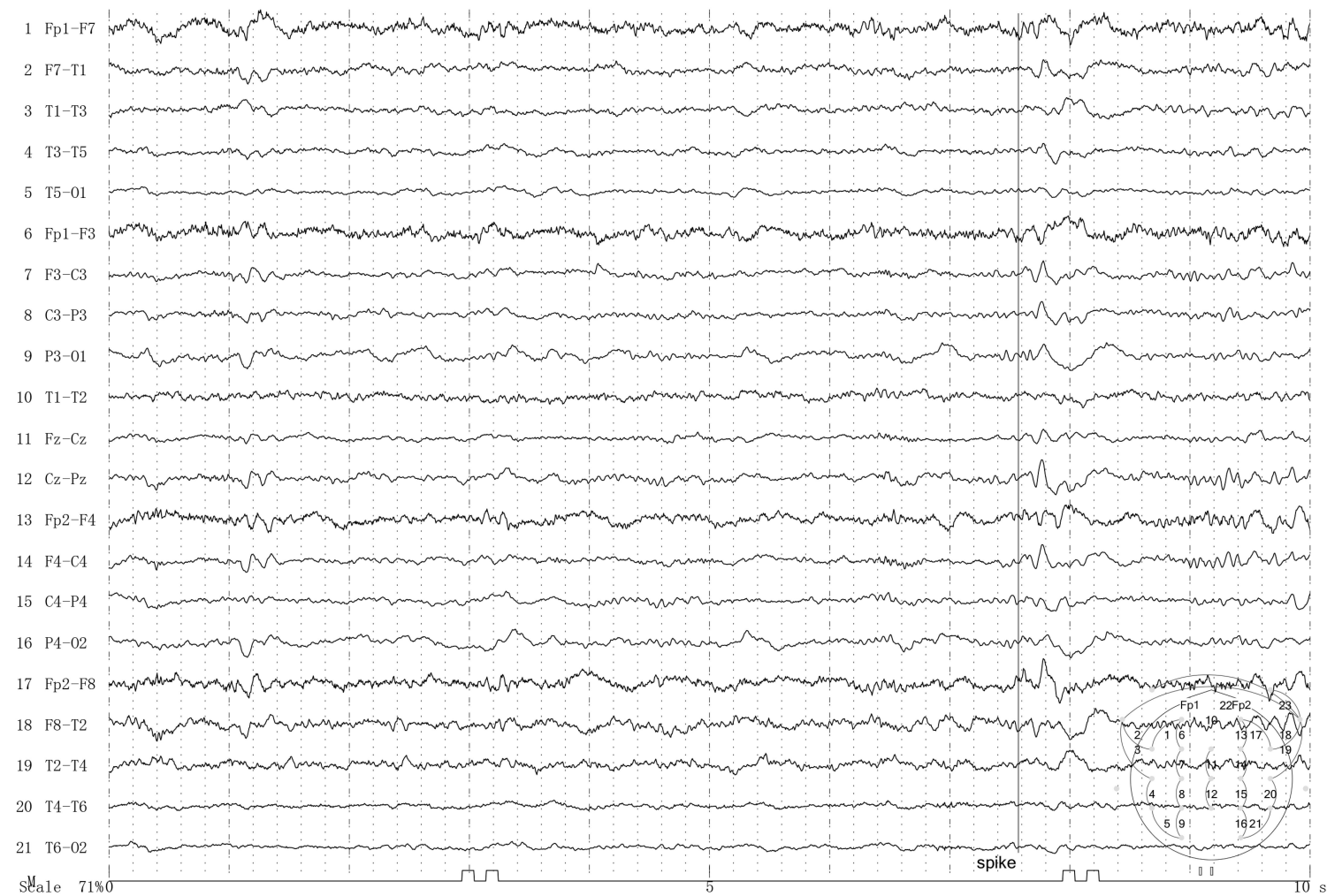

Figure 2 EEG of patient 14. (A) Slow waves during wakefulness. (B) Intermittent discharge.

(Figure 5). Four patients (20\%) experienced clinical relapses. Three patients experienced recurrent seizures because they failed to take oral prednisone on time as prescribed by the doctor, and they achieved relief after standard treatment. Additionally, one patient experienced seizures again 4 months after being discharged from the 


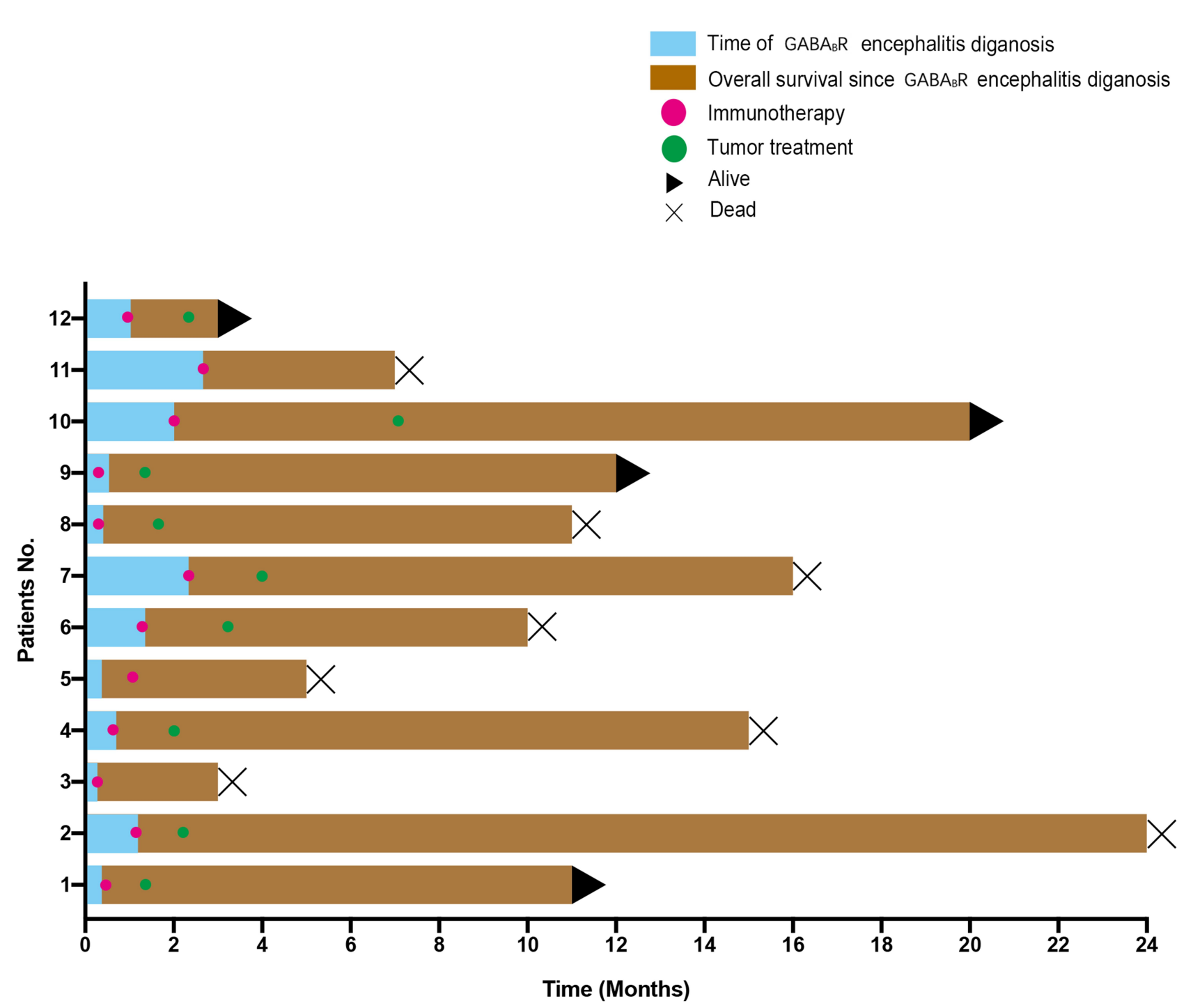

Figure 3 Treatment and survival of patients with $G_{A B A} R$ encephalitis presenting with SCLC.

hospital and was subsequently admitted to our institution. However, the patient's family refused further treatment, and the patient died of SE one year later.

\section{Prognostic Factors}

Factors related to the prognosis of $\mathrm{GABA}_{\mathrm{B}} \mathrm{R}$ encephalitis were analysed. The comparison between groups with a good prognosis and poor prognosis is summarized in Table 2. In terms of baseline characteristics, the average age of onset in the poor prognosis group was older than in the good prognosis group ( $\mathrm{P}=0.031)$. No significant differences in clinical characteristics or the results of auxiliary examinations were observed between the two groups. Regarding treatment, the time to initial improvement after the initiation of immunotherapy was related to the prognosis $(\mathrm{P}=0.038)$. Furthermore, the occurrence of respiratory failure was significantly related to the prognosis $(\mathrm{P}=0.038)$. Due to the small number of patients, multivariate analysis could not be performed.

\section{Discussion}

$\mathrm{GABA}_{\mathrm{B}} \mathrm{R}$ encephalitis is a rare type of autoimmune encephalitis. ${ }^{5}$ In this study, 20 patients who were diagnosed with $\mathrm{GABA}_{\mathrm{B}} \mathrm{R}$ encephalitis were reported, and the factors that may affect the prognosis of Chinese patients with $\mathrm{GABA}_{\mathrm{B}} \mathrm{R}$ encephalitis were evaluated. Three novel findings were obtained: (1) immunotherapy and tumour treatment may lead to a better prognosis and longer survival time for patients with $\mathrm{GABA}_{\mathrm{B}} \mathrm{R}$ encephalitis; (2) the serum $\mathrm{CD} 19^{+} \mathrm{B}$ cell percentage may be an indicator of disease activity for $\mathrm{GABA}_{\mathrm{B}} \mathrm{R}$ encephalitis; and (3) age, 


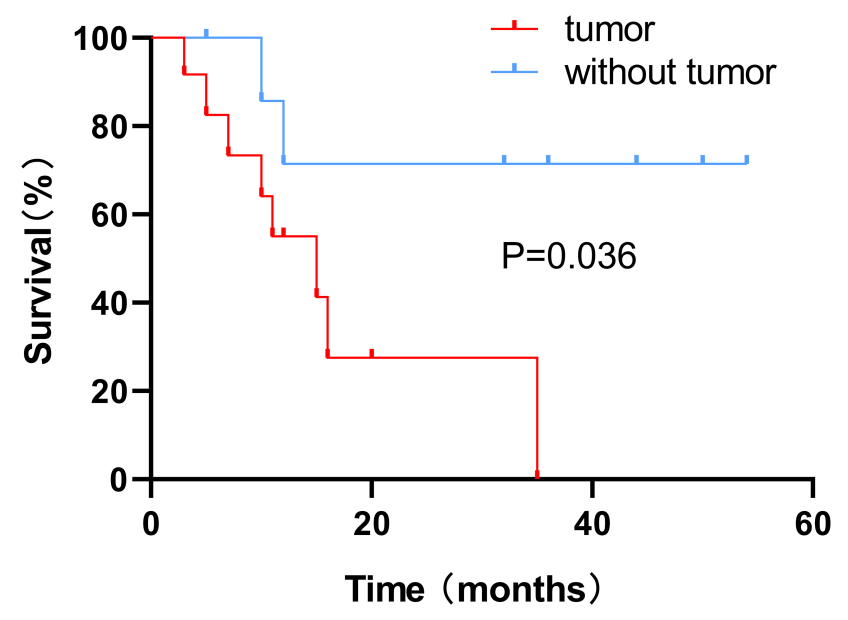

Figure 4 Kaplan-Meier survival curves showing a greater risk of death for patients with tumours than patients without tumours $(P=0.036)$.

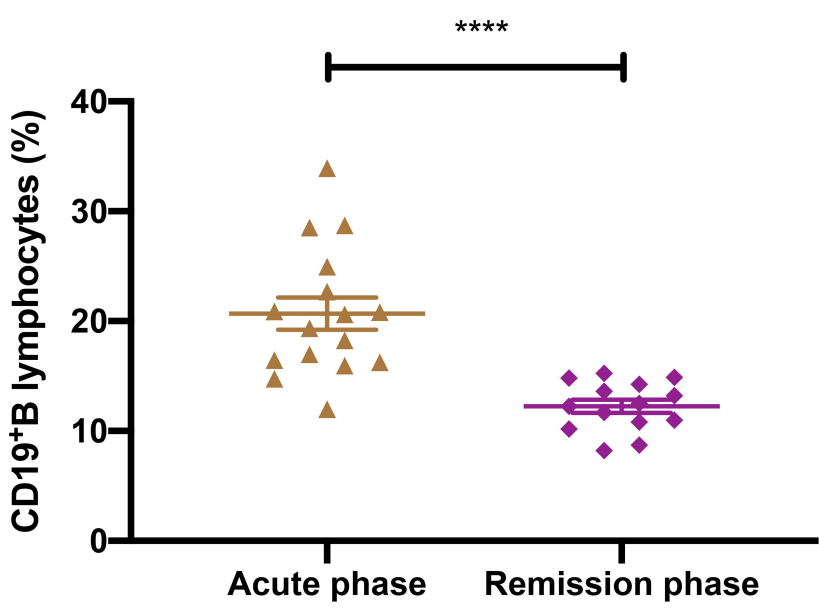

Figure 5 Comparison of the serum $\mathrm{CD} / 9^{+} \mathrm{B}$ cell percentage in patients with $\mathrm{GABA}_{B} \mathrm{R}$ encephalitis in the acute and remission phases. $* * * * \mathrm{P}<0.0 \mathrm{I}$.

the time to initial improvement after immunotherapy, and respiratory failure may be related to prognosis.

In our cohort, age was significantly related to the prognosis, and patients in the poor prognosis group were older at disease onset than patients in the good prognosis group ( $\mathrm{P}=0.031)$. The initial symptom of most patients was seizures, but subsequent manifestations included other typical symptoms, which warranted a prompt consideration of $\mathrm{GABA}_{\mathrm{B}} \mathrm{R}$ encephalitis, and this progressive process was consistent with previous research. ${ }^{15}$ Some atypical symptoms, including cerebellar ataxia, ocular clonusmyoclonus syndrome, and brainstem encephalitis, have been previously reported. ${ }^{16-18}$ Two of our patients also presented gait ataxia and brainstem encephalitis. GABA $_{B}$ Rs are widely distributed in the central nervous system, including the cerebral cortex, hippocampus, thalamus, cerebellum, pons and medulla oblongata. ${ }^{19}$ For this reason, more clinical manifestations and "atypical" cases may be discovered in the future. More than half of the patients (55\%) had hyperintensities on MRI-FLAIR or T2weighted MRI, consistent with the results of previous studies. $^{5,20-24}$ For patients with negative MRI results, brain FDG-PET may be an effective supplementary test. $^{25}$ In this study, FDG-PET revealed bilateral hippocampal hypermetabolism in one patient, which may have been related to the inflammatory process at the site. In future research, more studies are needed to determine the value of FDG-PET scans.

Approximately half of patients with $\mathrm{GABA}_{\mathrm{B}}$ $\mathrm{R}$ encephalitis have a history of cancer, and the most common type of cancer is SCLC, which is usually detected 2 to 47 weeks after the onset of neurological symptoms. ${ }^{8,15}$ Other tumours have also been reported, including thymic carcinoid, ${ }^{24}$ type B1 thymoma, ${ }^{26}$ melanoma, ${ }^{16}$ breast cancer, rectal cancer, multiple myeloma and oesophageal cancer. ${ }^{18,27}$ In our study, 12 patients $(60 \%)$ had SCLC, and no other tumours were detected. SCLC is the main cause of death in patients with GABA $_{B}$ encephalitis. $^{28}$ Among the 11 patients with a poor prognosis, $8(72.7 \%)$ died due to tumour progression, and the survival time of patients with tumours was shorter than patients without tumours (Figure 4). The treatment of SCLC effectively contributes to improvements in the neurological function of patients with paraneoplastic limbic encephalitis. $^{29}$ A worsening of symptoms could, in contrast, suggest incomplete resection, recurrence or secondary metastasis. Figure 3 shows the treatment and outcomes of patients with SCLC in this study, and patients who received tumour treatment had a better prognosis and longer survival time than patients who did not receive tumour treatment $(\mathrm{P}=0.025)$. Importantly, in two of our patients, tumours were not detected in the initial screen but were observed after 6 months. Therefore, even if no tumour is detected when encephalitis is diagnosed, regular screening is necessary. However, a significant difference in the presence of tumours was not observed between the good and poor prognosis groups $(\mathrm{P}=0.362)$, which is not consistent with the results of previous studies. ${ }^{6}$ The small number of patients in this study may be the main reason. Secondly, this discrepancy may be because the majority of patients received tumour treatment, and some patients experienced a relatively short follow-up time. 
Table 2 Characteristics of Patients and Comparisons Between the Good Outcome Group and the Poor Outcome Group

\begin{tabular}{|c|c|c|c|c|}
\hline & Total $(n=20)$ & Good Outcome $(n=9)$ & Poor Outcome $(n=\mid I)$ & p-value \\
\hline Age (years) & $59.35 \pm 9.20$ & $54.56 \pm 8.88$ & $63.27 \pm 7.75$ & $0.031^{\mathrm{a}}$ \\
\hline Sex (male) & $12(60.0 \%)$ & $5(55.6 \%)$ & 7 (63.6\%) & 1.000 \\
\hline Smoking history & $10(50.0 \%)$ & $5(55.6 \%)$ & $5(45.5 \%)$ & 1.000 \\
\hline \multicolumn{5}{|l|}{ Clinical information } \\
\hline Seizure & $18(90.0 \%)$ & 7 (77.8\%) & II (I00\%) & 0.189 \\
\hline SE & $10(50.0 \%)$ & $4(44.4 \%)$ & $6(54.5 \%)$ & 1.000 \\
\hline Cognitive deficits & 17 (85.0\%) & 7 (77.8\%) & $10(90.9 \%)$ & 0.566 \\
\hline Psychiatric disorders & 14 (70.0\%) & $6(66.7 \%)$ & 8 (72.7\%) & 1.000 \\
\hline Disturbance of consciousness & 14 (70.0\%) & $5(55.6 \%)$ & $9(81.8 \%)$ & 0.336 \\
\hline Movement disorders & $2(10.0 \%)$ & $2(22.2 \%)$ & $0(0.0 \%)$ & 0.189 \\
\hline Tumour & $12(60.0 \%)$ & $4(44.4 \%)$ & $8(72.7 \%)$ & 0.362 \\
\hline$m R S$ score $\geq$ at the peak of disease & $16(80.0 \%)$ & 7 (77.8\%) & $9(81.8 \%)$ & 1.000 \\
\hline \multicolumn{5}{|l|}{ Complementary tests } \\
\hline Abnormal MRI & II (55.0\%) & $6(66.7 \%)$ & $5(45.5 \%)$ & 0.406 \\
\hline Abnormal EEG & 15 (75.0\%) & $6(66.7 \%)$ & $9(81.8 \%)$ & 0.617 \\
\hline Abnormal CSF pressure $\left(>180 \mathrm{mmH}_{2} \mathrm{O}\right)$ & $2(10.0 \%)$ & I (II.I\%) & I (9.1\%) & 1.000 \\
\hline CSF WBC count $\left(\times 10^{6}\right)$ & $16.5(0-118)$ & $15(0-48)$ & $17(1-118)$ & 0.412 \\
\hline CSF protein $(g / L)$ & $0.37(0.19-0.66)$ & $0.34(0.19-0.66)$ & $0.37(0.21-0.59)$ & 0.412 \\
\hline Serum $G_{A B A}$ antibody strongly positive & $7(35.0 \%)$ & $3(33.3 \%)$ & $4(36.4 \%)$ & 1.000 \\
\hline CSF $\mathrm{GABA}_{\mathrm{B}}$ antibody strongly positive & $3(15.0 \%)$ & I (II.I\%) & $2(18.2 \%)$ & \\
\hline \multicolumn{5}{|l|}{ Immunotherapy } \\
\hline $\begin{array}{l}\text { Time to the initiation of treatment after symptom } \\
\text { onset (days) }\end{array}$ & $16(6-130)$ & $14(9-60)$ & $28(6-130)$ & 0.331 \\
\hline Only MTP & $5(25.0 \%)$ & $2(22.2 \%)$ & $3(27.3 \%)$ & 1.000 \\
\hline MTP + IVlg & $15(75.0 \%)$ & 7 (77.8\%) & $8(72.7 \%)$ & 1.000 \\
\hline Second-line immunotherapy & 7 (35.0\%) & $3(33.3 \%)$ & $4(36.4 \%)$ & \\
\hline Time to initial improvement $>4$ weeks & $5(25.0 \%)$ & $0(0.0 \%)$ & 5 (45.5\%) & $0.038^{\mathrm{a}}$ \\
\hline \multicolumn{5}{|l|}{ Complications } \\
\hline Pneumonia & $10(50.0 \%)$ & $3(33.3 \%)$ & $7(63.6 \%)$ & 0.370 \\
\hline Respiratory failure & $5(25.0 \%)$ & $0(0.0 \%)$ & 5 (45.5\%) & $0.038^{\mathrm{a}}$ \\
\hline Admission to ICU & $4(20.0 \%)$ & I (II.I\%) & $3(27.3 \%)$ & 0.319 \\
\hline
\end{tabular}

Abbreviations: SE, status epilepticus; mRS, modified Rankin Scale; MRI, magnetic resonance imaging; EEG, electroencephalography; CSF, cerebrospinal fluid; MTP,

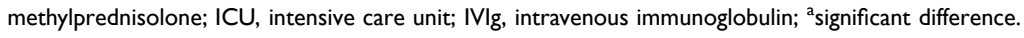

Antiepileptic drugs appear to be ineffective against seizures caused by $\mathrm{GABA}_{\mathrm{B}} \mathrm{R}$ encephalitis, but immunotherapy is crucial. ${ }^{30}$ Previous studies have shown most patients with $\mathrm{GABA}_{\mathrm{B}} \mathrm{R}$ encephalitis received immunotherapy showed improvement in neurological function, such as Lancaster reported in the United States of America (USA) (10/13, $76.9 \%),{ }^{5}$ Maureille reported in Germany $(15 / 20,75.0 \%),{ }^{15}$ and Guan reported in China $(15 / 18,83.3 \%) .{ }^{23}$ All patients in our cohort received immunotherapy, and $70 \%$ of them displayed improved neurological function within 10 days after the initiation of first-line immunotherapy. The median mRS scores of all patients decreased from 4 (range: $3-5$ ) to 3 (range: 2-5) after treatment with first-line immunotherapy $(\mathrm{P}<0.01)$. In a retrospective cohort study of patients with
NMDAR encephalitis, the efficacy rate of first-line therapy was slightly higher than $50 \% .{ }^{13}$ The difference in responses of patients with different types of autoimmune encephalitis to immunotherapy may explain this finding. In fact, the combination of corticosteroids and IVIG therapy administered to most of our patients may also have been a factor, because the use of combination therapy may produce a better response than the use of a single therapy. ${ }^{29}$ For patients who do not respond to first-line immunotherapy after 10 days, second-line therapy should be applied. ${ }^{31}$ Accelerated second-line immunotherapy is related to a good prognosis for patients with NMDAR encephalitis. ${ }^{13}$ Seven patients received second-line immunotherapy, and the mRS scores of these patients were 3 
(range: $2-5$ ) and 2 (range: $1-3$ ) before and after second-line immunotherapy, respectively $(\mathrm{P}=0.015)$. Rituximab is an optional therapeutic agent for patients with autoimmune encephalitis who exhibit poor first-line treatment responses, and it has been extensively studied in patients with NMDAR encephalitis and neuromyelitis optica spectrum diseases (NMOSD). ${ }^{32,33}$ Patient 10 showed no improvement in neurological function after 12 days of first-line treatment with MTP plus IVIG and was subsequently treated with rituximab. The neurological function significantly improved before discharge and the mRS score decreased from 4 to 2 . After 32 months of follow-up, she had a good outcome $(\mathrm{mRS}=1)$. Insufficient immunotherapy, including secondline treatments, may be a factor related to only partial recovery. ${ }^{25}$ According to our research, first-line therapy with a combination of corticosteroids and IVIG and secondline therapy with rituximab may be an effective choice. However, considering the small number of patients, the superiority of different immunotherapies remains unclear. A large number of additional patients with long-term follow-up data are needed to determine the appropriate treatment plan and prognosis of this rare disease. Moreover, recent reports have documented the utility of the time to first recorded clinical improvement after treatment initiation as an indicator to predict the 1-year functional status of patients with NMDAR encephalitis. ${ }^{34}$ The time in the poor prognosis group was longer for patients with $\mathrm{GABA}_{\mathrm{B}} \mathrm{R}$ encephalitis than in the good prognosis group $(\mathrm{P}=0.038)$, which may have been due to the differences in the severity of disease and the responses to immunotherapy.

Lung infection was the most common complication. Respiratory failure was related to the prognosis $(\mathrm{P}=0.038)$, consistent with the results of a previous study. ${ }^{35}$ However, we did not find a clear link between admission to the ICU and a poor prognosis $(\mathrm{P}=0.319)$. The ICU hospitalization rate of our patients was lower than in developed countries $(20 \%$ vs $64 \%),{ }^{15}$ and the high costs may have been the main reason. Therefore, the ICU hospitalization rate may be underestimated in this study.

High antibody titres are associated with a poor prognosis of NMDAR encephalitis. ${ }^{36}$ However, in our patients with $\mathrm{GABA}_{B} \mathrm{R}$ encephalitis, we did not observe a relationship between antibody titres and the prognosis. Some patients were still positive for antibodies, even after clinical recovery. ${ }^{37,38}$ Unfortunately, $\mathrm{GABA}_{\mathrm{B}} \mathrm{R}$ antibodies were not detected in the four relapsed patients, and thus we were unable to evaluate the relationship between antibody titres and relapse. Future studies should investigate whether antibody titres predict disease activity and the need for long-term immunotherapy.

The pathogenesis of $\mathrm{GABA}_{\mathrm{B}} \mathrm{R}$ encephalitis is currently unclear. The expression of $\mathrm{GABA}_{\mathrm{B}} \mathrm{Rs}$ in tumour tissues may be an important factor, such as in lung cancer and thymoma. ${ }^{22,26}$ The expression of this protein may reduce immune tolerance and make it an autoantigen, which in turn might induce a series of immune responses. The relationship between B lymphocytes and autoimmune diseases has been confirmed, such as in multiple sclerosis and NMOSD. ${ }^{39,40}$ In NMOSD, the serum $\mathrm{CD} 19^{+} \mathrm{B}$ cell percentage is an important monitoring index for evaluating efficacy of patients, ${ }^{41}$ and relapse mostly occurs in the proliferation stage of B lymphocyte. ${ }^{39}$ In autoimmune encephalitis, patients treated with rituximab are required to regularly monitor the serum $\mathrm{CD} 19+\mathrm{B}$ cell percentage, ${ }^{32}$ and it may be related to disease activity and relapse. Therefore, the percentage of serum lymphocytes in sixteen patients before immunotherapy and fourteen patients at the last follow-up were detected. The disease activity or clinical remission might be closely related to the serum $\mathrm{CD} 19^{+} \mathrm{B}$ cell percentage (Figure 5) $(\mathrm{P}<0.01)$. Moreover, regardless of the presence of intrathecal synthesis in patients with $\mathrm{GABA}_{\mathrm{B}} \mathrm{R}$ encephalitis, the peripheral humoral immune system is extremely active. This finding also provides theoretical support for B lymphocyte depletion therapy, such as rituximab. Interestingly, $\mathrm{CD} 8^{+}$ $\mathrm{T}$ cells also appear to be involved in the pathogenesis of the disease. ${ }^{15,42}$ We further speculate that in patients with $\mathrm{GABA}_{\mathrm{B}} \mathrm{R}$ encephalitis, the reaction of antibodies and receptors may play an important role in the initiation of the disease. Seizures then activate the neuronal expression of major histocompatibility complex (MHC) class I molecules and other neuronal proteins, ${ }^{43,44}$ which may cause $\mathrm{CD}^{+} \mathrm{T}$ cells to target neurons, causing irreversible nerve damage. This result may explain why some of our patients had long-term memory deficits. Therefore, early diagnosis and treatment may reduce residual symptoms. However, since we only examined the percentage of $\mathrm{CD}^{+} \mathrm{T}$ cells in serum, we were unable to determine the change in their absolute values in different periods. Further testing of immune cell subsets in CSF is required for a better treatment plan.

Our study had some limitations. The main limitation was the small number of patients due to the rarity of the disease. In addition, retrospective studies may also lead to 
incomplete data. Therefore, prospective studies with larger cohorts are needed.

\section{Conclusion}

Aggressive immunotherapy and tumour treatment contribute to improvements in neurological function and the prognosis. The serum $\mathrm{CD} 19^{+} \mathrm{B}$ cell percentage may be an indicator of disease activity. Older age, delayed initial improvement after immunotherapy ( $>4$ weeks) and respiratory failure may be predictors of a poor prognosis.

\section{Ethics Approval}

The authors assert that all procedures contributing to this work comply with the Declaration of Helsinki in 1975, as revised in 2008.

\section{Consent for Publication}

Informed consent was obtained from all patients. The study was approved by the Research Ethics Committee of Shandong Provincial Hospital Affiliated to Shandong University.

\section{Acknowledgments}

We would like to thank all of the patients who participated in this study.

\section{Author Contributions}

All authors made substantial contributions to conception and design, acquisition of data, or analysis and interpretation of data; took part in drafting the article or revising it critically for important intellectual content; agreed to submit to the current journal; gave final approval of the version to be published; and agree to be accountable for all aspects of the work.

\section{Funding}

This study was supported by the National Natural Science Foundation of China (No.81671183).

\section{Disclosure}

The authors report no conflicts of interest related to this study.

\section{References}

1. Dalmau J, Tuzun E, Wu HY, et al. Paraneoplastic anti-N-methylD-aspartate receptor encephalitis associated with ovarian teratoma. Ann Neurol. 2007;61(1):25-36. doi:10.1002/ana.21050
2. Chefdeville A, Honnorat J, Hampe CS, Desestret V. Neuronal central nervous system syndromes probably mediated by autoantibodies. Eur $J$ Neurosci. 2016;43(12):1535-1552. doi:10.1111/ejn.13212

3. Nosadini M, Mohammad SS, Ramanathan S, Brilot F, Dale RC. Immune therapy in autoimmune encephalitis: a systematic review. Expert Rev Neurother. 2015;15(12):1391-1419. doi:10.1586/1473 7175.2015.1115720

4. Benarroch EE. GABAB receptors: structure, functions, and clinical implications. Neurology. 2012;78(8):578-584. doi:10.1212/WNL.0b $013 \mathrm{e} 318247 \mathrm{~cd} 03$

5. Lancaster E, Lai M, Peng X, et al. Antibodies to the GABA(B) receptor in limbic encephalitis with seizures: case series and characterisation of the antigen. Lancet Neurol. 2010;9(1):67-76. doi:10. 1016/S1474-4422(09)70324-2

6. Hoftberger R, Titulaer MJ, Sabater L, et al. Encephalitis and GABAB receptor antibodies: novel findings in a new case series of 20 patients. Neurology. 2013;81(17):1500-1506. doi:10.1212/WNL.0b013e318 2a9585f

7. Cho JJ, Wymer JP. Paraneoplastic lambert-eaton myasthenic syndrome with limbic encephalitis: clinical correlation with the coexistence of Anti-VGCC and Anti-GABAB receptor antibodies. J Clin Neuromuscul Dis. 2017;19(2):84-88. doi:10.1097/CND.0000000000000192

8. McKay JH, Dimberg EL, Lopez Chiriboga AS. A systematic review of gamma-aminobutyric acid receptor type B autoimmunity. Neurol Neurochir Pol. 2019;53(1):1-7. doi:10.5603/PJNNS.a2018.0005

9. Kalemkerian GP. Small cell lung cancer. Semin Respir Crit Care Med. 2016;37(5):783-796. doi:10.1055/s-0036-1592116

10. Graus F, Titulaer MJ, Balu R, et al. A clinical approach to diagnosis of autoimmune encephalitis. Lancet Neurol. 2016;15(4):391-404. doi:10.1016/S1474-4422(15)00401-9

11. Shin YW, Lee ST, Park KI, et al. Treatment strategies for autoimmune encephalitis. Ther Adv Neurol Disord. 2018;11:17562856 17722347. doi:10.1177/1756285617722347

12. Glatzer M, Rittmeyer A, Muller J, et al. Treatment of limited disease small cell lung cancer: the multidisciplinary team. Eur Respir J. 2017;50:1700422. doi:10.1183/13993003.00422-2017

13. Titulaer MJ, McCracken L, Gabilondo I, et al. Treatment and prognostic factors for long-term outcome in patients with anti-NMDA receptor encephalitis: an observational cohort study. Lancet Neurol. 2013;12(2):157-165. doi:10.1016/S1474-4422(12)70310-1

14. Zekeridou A, Karantoni E, Viaccoz A, et al. Treatment and outcome of children and adolescents with N-methyl-D-aspartate receptor encephalitis. $J$ Neurol. 2015;262(8):1859-1866. doi:10.1007/s00 415-015-7781-9

15. Maureille A, Fenouil T, Joubert B, et al. Isolated seizures are a common early feature of paraneoplastic anti-GABAB receptor encephalitis. J Neurol. 2019;266(1):195-206. doi:10.1007/s00415018-9132-0

16. Jarius S, Steinmeyer F, Knobel A, et al. GABAB receptor antibodies in paraneoplastic cerebellar ataxia. J Neuroimmunol. 2013;256(1-2):94-96. doi:10.1016/j.jneuroim.2012.12.006

17. DeFelipe-Mimbrera A, Masjuan J, Corral I, Villar LM, Graus F, GarciaBarragan N. Opsoclonus-myoclonus syndrome and limbic encephalitis associated with GABAB receptor antibodies in CSF. J Neuroimmunol. 2014;272(1-2):91-93. doi:10.1016/j.jneuroim.2014.04.009

18. Mundiyanapurath S, Jarius S, Probst C, Stocker W, Wildemann B, Bosel J. GABA-B-receptor antibodies in paraneoplastic brainstem encephalitis. J Neuroimmunol. 2013;259(1-2):88-91. doi:10.1016/j. jneuroim.2013.04.004

19. Billinton A, Ige AO, Wise A, et al. GABA(B) receptor heterodimer-component localisation in human brain. Brain Res $\mathrm{Mol}$ Brain Res. 2000;77(1):111-124. doi:10.1016/s0169-328x(00)00047-4

20. Qiao S, Zhang YX, Zhang BJ, et al. Clinical, imaging, and follow-up observations of patients with anti-GABAB receptor encephalitis. Int $J$ Neurosci. 2017;127(5):379-385. doi:10.1080/00207454.2016.11 76922 
21. Cui J, Bu H, He J, et al. The gamma-aminobutyric acid-B receptor (GABAB) encephalitis: clinical manifestations and response to immunotherapy. Int J Neurosci. 2018;128(7):627-633. doi:10.1080/ 00207454.2017 .1408618

22. Zhao XH, Yang X, Liu XW, Wang SJ. Clinical features and outcomes of Chinese patients with anti-gamma-aminobutyric acid B receptor encephalitis. Exp Ther Med. 2020;20(1):617-622. doi:10.3892/ etm.2020.8684

23. Guan HZ, Ren HT, Yang XZ, et al. Limbic encephalitis associated with anti-gamma-aminobutyric acid b receptor antibodies: a case series from China. Chin Med J. 2015;128(22):3023-3028. doi:10.4103/0366-6999.168989

24. Boronat A, Sabater L, Saiz A, Dalmau J, Graus F. GABA(B) receptor antibodies in limbic encephalitis and anti-GAD-associated neurologic disorders. Neurology. 2011;76(9):795-800. doi:10.1212/WNL.0b0 $13 \mathrm{e} 31820 \mathrm{e} 7 \mathrm{~b} 8 \mathrm{~d}$

25. Kim TJ, Lee ST, Shin JW, et al. Clinical manifestations and outcomes of the treatment of patients with GABAB encephalitis. J Neuroimmunol. 2014;270(1-2):45-50. doi:10.1016/j.jneuroim.2014.02.011

26. Alexopoulos H, Dagklis IE, Akrivou S, Bostantjopoulou S, Dalakas MC. Autoimmune encephalitis with GABAB antibodies, thymoma, and GABAB receptor thymic expression. Neurol Neuroimmunol Neuroinflamm. 2014;1(4):e39. doi:10.1212/NXI.00 00000000000039

27. Jeffery OJ, Lennon VA, Pittock SJ, Gregory JK, Britton JW, McKeon A. GABAB receptor autoantibody frequency in service serologic evaluation. Neurology. 2013;81(10):882-887. doi:10.1212/ WNL.0b013e3182a35271

28. Lin J, Li C, Li A, et al. Encephalitis with antibodies against the GABAB receptor: high mortality and risk factors. Front Neurol. 2019;10:1030. doi:10.3389/fneur.2019.01030

29. Shen $\mathrm{K}, \mathrm{Xu} \mathrm{Y,} \mathrm{Guan} \mathrm{H,} \mathrm{et} \mathrm{al.} \mathrm{Paraneoplastic} \mathrm{limbic} \mathrm{encephalitis}$ associated with lung cancer. Sci Rep. 2018;8(1):6792. doi:10.1038/ s41598-018-25294-y

30. de Bruijn M, van Sonderen A, van Coevorden-hameete $\mathrm{MH}$, et al. Evaluation of seizure treatment in anti-LGI1, anti-NMDAR, and anti-GABABR encephalitis. Neurology. 2019;92(19):e2185-e2196. doi:10.1212/WNL.0000000000007475

31. Dalmau J, Lancaster E, Martinez-Hernandez E, Rosenfeld MR, Balice-Gordon R. Clinical experience and laboratory investigations in patients with anti-NMDAR encephalitis. Lancet Neurol. 2011;10 (1):63-74. doi:10.1016/S1474-4422(10)70253-2

32. Wang BJ, Wang CJ, Zeng ZL, Yang Y, Guo SG. Lower dosages of rituximab used successfully in the treatment of anti-NMDA receptor encephalitis without tumour. J Neurol Sci. 2017;377:127-132. doi:10.1016/j.jns.2017.04.007
33. Yang CS, Yang L, Li T, et al. Responsiveness to reduced dosage of rituximab in Chinese patients with neuromyelitis optica. Neurology. 2013;81(8):710-713. doi:10.1212/WNL.0b013e3182alaac7

34. Balu R, McCracken L, Lancaster E, Graus F, Dalmau J, Titulaer MJ. A score that predicts 1-year functional status in patients with anti-NMDA receptor encephalitis. Neurology. 2019;92(3):e244e252. doi:10.1212/WNL.0000000000006783

35. Singh TD, Fugate JE, Rabinstein AA. The spectrum of acute encephalitis: causes, management, and predictors of outcome. Neurology. 2015;84(4):359-366. doi:10.1212/WNL.0000000000001190

36. Gresa-Arribas N, Titulaer MJ, Torrents A, et al. Antibody titres at diagnosis and during follow-up of anti-NMDA receptor encephalitis: a retrospective study. Lancet Neurol. 2014;13(2):167-177. doi:10. 1016/S1474-4422(13)70282-5

37. Hansen HC, Klingbeil C, Dalmau J, Li W, Weissbrich B, Wandinger KP. Persistent intrathecal antibody synthesis 15 years after recovering from anti-N-methyl-D-aspartate receptor encephalitis. JAMA Neurol. 2013;70 (1):117-119. doi:10.1001/jamaneurol.2013.585

38. Alexopoulos H, Kosmidis ML, Dalmau J, Dalakas MC. Paraneoplastic anti-NMDAR encephalitis: long term follow-up reveals persistent serum antibodies. $J$ Neurol. 2011;258 (8):1568-1570. doi:10.1007/s00415-011-5982-4

39. Pellkofer HL, Krumbholz M, Berthele A, et al. Long-term follow-up of patients with neuromyelitis optica after repeated therapy with rituximab. Neurology. 2011;76(15):1310-1315. doi:10.1212/WNL.0b $013 \mathrm{e} 3182152881$

40. Stuve O, Leussink VI, Frohlich R, et al. Long-term B-lymphocyte depletion with rituximab in patients with relapsing-remitting multiple sclerosis. Arch Neurol. 2009;66(2):259-261. doi:10.1001/archneurol. 2008.551

41. Yang Y, Wang CJ, Wang BJ, Zeng ZL, Guo SG. Comparison of efficacy and tolerability of azathioprine, mycophenolate mofetil, and lower dosages of rituximab among patients with neuromyelitis optica spectrum disorder. J Neurol Sci. 2018;385:192-197. doi:10.1016/j.jns.2017.12.034

42. Golombeck KS, Bonte K, Monig C, et al. Evidence of a pathogenic role for $\mathrm{CD} 8(+) \mathrm{T}$ cells in anti-GABAB receptor limbic encephalitis. Neurol Neuroimmunol Neuroinflamm. 2016;3(3):e232. doi:10.1212/ NXI.0000000000000232

43. Corriveau RA, Huh GS, Shatz CJ. Regulation of class I MHC gene expression in the developing and mature CNS by neural activity. Neuron. 1998;21(3):505-520. doi:10.1016/s0896-6273(00)80562-0

44. Neumann H, Cavalie A, Jenne DE, Wekerle H. Induction of MHC class I genes in neurons. Science. 1995;269(5223):549-552. doi:10. $1126 /$ science. 7624779
Neuropsychiatric Disease and Treatment

\section{Publish your work in this journal}

Neuropsychiatric Disease and Treatment is an international, peerreviewed journal of clinical therapeutics and pharmacology focusing on concise rapid reporting of clinical or pre-clinical studies on a range of neuropsychiatric and neurological disorders. This journal is indexed on PubMed Central, the 'PsycINFO' database and CAS, and is the official journal of The International Neuropsychiatric Association (INA). The manuscript management system is completely online and includes a very quick and fair peer-review system, which is all easy to use. Visit http://www.dovepress.com/testimonials.php to read real quotes from published authors. 